\title{
Physical activity patterns across time- segmented youth sport flag football practice
}

\author{
Chelsey R. Schlechter ${ }^{1,2 *}$, Justin M. Guagliano ${ }^{1}$, Richard R. Rosenkranz ${ }^{3}$, George A. Milliken ${ }^{4}$
} and David A. Dzewaltowski ${ }^{2,5}$

\begin{abstract}
Background: Youth sport (YS) reaches a large number of children world-wide and contributes substantially to children's daily physical activity (PA), yet less than half of YS time has been shown to be spent in moderate-tovigorous physical activity (MVPA). Physical activity during practice is likely to vary depending on practice structure that changes across YS time, therefore the purpose of this study was 1) to describe the type and frequency of segments of time, defined by contextual characteristics of practice structure, during YS practices and 2) determine the influence of these segments on PA.

Methods: Research assistants video-recorded the full duration of 28 practices from 14 boys' flag football teams ( 2 practices/team) while children concurrently ( $N=111$, aged $5-11$ years, mean $7.9 \pm 1.2$ years) wore ActiGraph GT1M accelerometers to measure PA. Observers divided videos of each practice into continuous context time segments ( $N=204$; mean-segments-per-practice $=7.3, S D=2.5)$ using start/stop points defined by change in context characteristics, and assigned a value for task (e.g., management, gameplay, etc.), member arrangement (e.g., small group, whole group, etc.), and setting demand (i.e., fosters participation, fosters exclusion). Segments were then paired with accelerometer data. Data were analyzed using a multilevel model with segment as unit of analysis.

Results: Whole practices averaged $34 \pm 2.4 \%$ of time spent in MVPA. Free-play $(51.5 \pm 5.5 \%)$, gameplay $(53.6 \pm 3.7 \%)$, and warm-up (53.9 $\pm 3.6 \%)$ segments had greater percentage of time (\%time) in MVPA compared to fitness (36.8 \pm 4.4\%) segments ( $p \leq .01)$. Greater \%time was spent in MVPA during free-play segments compared to scrimmage (30. $2 \pm 4.6 \%)$, strategy $(30.6 \pm 3.2 \%)$, and sport-skill $(31.6 \pm 3.1 \%)$ segments $(p \leq .01)$, and in segments that fostered participation $(36.1 \pm 2.7 \%)$ than segments that fostered exclusion $(29.1 \pm 3.0 \% ; p \leq .01)$. Significantly greater \%time was spent in low-energy stationary behavior in fitness (15.7 $\pm 3.4 \%)$ than gameplay (4.0 $\pm 2.9 \%)$ segments $(p \leq .01)$, and in sport-skill $(17.6 \pm 2.2 \%)$ than free-play (8.2 $\pm 4.2 \%)$, gameplay, and warm-up (10.6 $\pm 2.6 \%)$ segments $(p<.05)$.

Conclusions: The \%time spent in low-energy stationary behavior and in MVPA differed by characteristics of task and setting demand of the segment. Restructuring the routine of YS practice to include segments conducive to MVPA could increase \%time spent in MVPA during practice. As YS reaches a large number of children worldwide, increasing PA during YS has the potential to create a public health impact.
\end{abstract}

Keywords: Moderate-to-vigorous physical activity, Organized sport, Youth, Lesson context, Direct observation, Video observation

\footnotetext{
* Correspondence: chelsey.schlechter@unmc.edu

${ }^{1}$ Department of Kinesiology, Kansas State University, Natatorium 1a,

Manhattan, KS 66506, USA

${ }^{2}$ College of Public Health, University of Nebraska Medical Center, 984365

Nebraska Medical Center, Omaha, NE 68198-4365, USA

Full list of author information is available at the end of the article
}

(c) The Author(s). 2018 Open Access This article is distributed under the terms of the Creative Commons Attribution 4.0 International License (http://creativecommons.org/licenses/by/4.0/), which permits unrestricted use, distribution, and reproduction in any medium, provided you give appropriate credit to the original author(s) and the source, provide a link to the Creative Commons license, and indicate if changes were made. The Creative Commons Public Domain Dedication waiver (http://creativecommons.org/publicdomain/zero/1.0/) applies to the data made available in this article, unless otherwise stated. 


\section{Background}

Current public health physical activity guidelines recommend that children accrue $60 \mathrm{~min}$ of moderate-tovigorous physical activity (MVPA) per day to achieve overall health benefits, including decreased cardiovascular and metabolic disease risk factors, increased bone density, muscular and cardiovascular fitness [1]. Despite these health benefits, surveillance estimates have indicated that only $42 \%$ of children and $8 \%$ of adolescents in the United States are meeting physical activity guidelines [2].

Of the $60 \mathrm{~min}$ of MVPA that children are suggested to accumulate daily, $30 \mathrm{~min}$ are recommended to come from time spent at school, and the remaining $30 \mathrm{~min}$ from out-of-school time [3]. One out-of-school setting that provides an opportunity to accumulate MVPA is youth sport $[4,5]$. Participation in youth sport has been shown to provide a myriad of psychological, social, and physical benefits for children, including increased health-related quality of life [6], social integration [7], and confidence [7]. In addition, children have been shown to accumulate more physical activity (PA) on youth sport days compared to non-sport days [8]. Despite providing an opportunity to accrue MVPA, much of youth sport time is spent sedentary or in light activity [8-12]. Many children worldwide participate in youth sport [13], therefore targeting YS as a setting to increase PA has the potential to reach a large number of children.

To identify periods of time when children are active and inactive, researchers have characterized the pattern of children's PA by segmenting across time and by contextual characteristics [14-19]. Within the day, children's PA has been segmented into morning and afternoon [16], before, during, and after-school [14, 19], indoor and outdoor [15-17], specific class periods such as recess and PE $[8,18]$, and hour by hour [19]. Despite the ability of accelerometers to provide a detailed timestamped assessment of the pattern of PA during shorter time frames such as the duration of a youth sport practice, to date studies reporting PA and context during youth sport have only reported mean activity and total percentage of time spent in various contextual conditions for the entire practice $[9,10]$. Though reporting average activity and context across an entire practice provides valuable information as to how practice time is spent, averaging PA across an entire practice does not allow for examining the heterogeneous peaks and valleys of activity that occur during a youth sport practice, and thus restricts researchers' ability to determine the processes that could be causing the variability in practice PA. Each youth sport practice can be considered a dynamic social system with multiple ecological processes that influence children's PA [20]. Examination of the continuous pattern of PA in synchrony with contextual characteristics during a youth sport practice is important to determine periods of time spent active or inactive during practice and in turn identify the ecological processes that are driving PA.

Researchers in youth activity settings have identified several ecological processes as potential drivers of PA (or inactivity), including task (e.g., management, freeplay, gameplay) [21], the setting member arrangement (e.g., whole group, small group) [16], and the demand of the setting (e.g., fosters participation, fosters exclusion) [22, 23]. In physical education, management and knowledge delivery contexts were found to have negative correlations with boys' MVPA [21]. In contrast, the authors found that gameplay and free-play both demonstrated a positive correlation with boys' MVPA [21]. In preschool, children were found to have a higher percentage of time spent in total physical activity while arranged in small group, compared to whole group [16]. In summer camps, elimination games (i.e., games that foster exclusion) have been shown to have lower amounts of MVPA than non-elimination games (i.e., games that foster participation) [23].

The purpose of this study was to describe the type and frequency of segments of time, defined by contextual characteristics, during youth sport (YS) practice, and determine the influence of these segments on physical activity (PA). We hypothesized that (1) practices would have heterogeneous time segments defined by contextual characteristics, (2) member arrangement and setting demand of the time segment would influence MVPA, and (3) time segments that demanded participation (i.e., optimal demand) would result in greater MVPA compared to segments that fostered exclusion (i.e., disadvantaged demand).

\section{Methods}

The protocol for this cross-sectional study (\#7289) was approved by the Institutional Review Board of the study authors' university.

\section{Setting}

Teams were recruited from a convenience sample of youth recreational flag football (i.e., a non-tackle variation of North American football) program run by the local Parks and Recreation of a Midwestern U.S. city (population $>50,000$ people). The program was divided into 3 leagues based on grade; all 24 teams in the 1st/ 2nd and 3rd/4th grade leagues were eligible to participate in the study. Each team was coached by a volunteer, and each coach determined the day, time, location, and duration of practice for the team. Teams practiced 1-2 times/week, and played 1 game/week. The season ran 
for 8 weeks, from the last week of August until the last week of October.

\section{Participants}

After coaches consented to participate in the study, all players on their team were invited to participate (Fig. 1). A total of 126 boys were eligible for participation, of which 112 provided parental informed consent (91\%). Only children with parental consent were included in the study. Analysis included 111, 5-11 year-old boys (mean age \pm standard deviation $=7.9 \pm 1.2$ years). Participant characteristics have been presented elsewhere [12].

\section{Outcome measures}

\section{Physical activity}

Physical activity was objectively measured using ActiGraph GT1M accelerometers (ActiGraph; Pensacola, FL). ActiGraph accelerometers are the most widely used accelerometers [24] and have been shown to provide a valid and reliable measure of physical activity in youth [25]. To capture the sporadic nature of youth during flag football, accelerometers were initialized to record in $15 \mathrm{~s}$ epochs [26] and cut-points by Evenson et al. [27] were applied to determine time spent sedentary $(\leq 100$ counts per minute; CPM), light (LPA; 101-2295 CPM), moderate (MPA; 2296-4011 CPM), and vigorous physical activity (VPA; $\geq 4012 \mathrm{CPM}$ ). Evenson cut-points are currently considered the most accurate estimation of PA for this age group [25]. Due to current calls to reach consensus on the definition of the term 'sedentary' we will hereafter refer to activity at or below 100 CPM as low-energy stationary behavior rather than sedentary [28].

\section{Video observation}

Video was recorded using the video capability of Apple ${ }^{\mathrm{Tx}}$ iPod Touch 5th Generation (California, USA) and a wide-angle lens. Two cameras recorded each practice, a belt-worn camera worn by the head coach and a camera fixed on top of a tripod and positioned to view the whole field.

\section{Contextual variables}

The coding scheme, definitions, and examples for each contextual variable are presented in Table 1 (See [22]). Each time segment was assigned a value for the task goal of the segment (task), the arrangement of members within the segment (member arrangement), and whether the segment fostered participation or fostered exclusion (setting demand). The categories for each contextual characteristic were determined by a review of the literature [22] and developed according to existing observation systems used for physical activity $[9,29]$ and education settings $[30,31]$. After a preliminary coding system was developed, a subsample of videos were coded by two research assistants for an inter-rater reliability

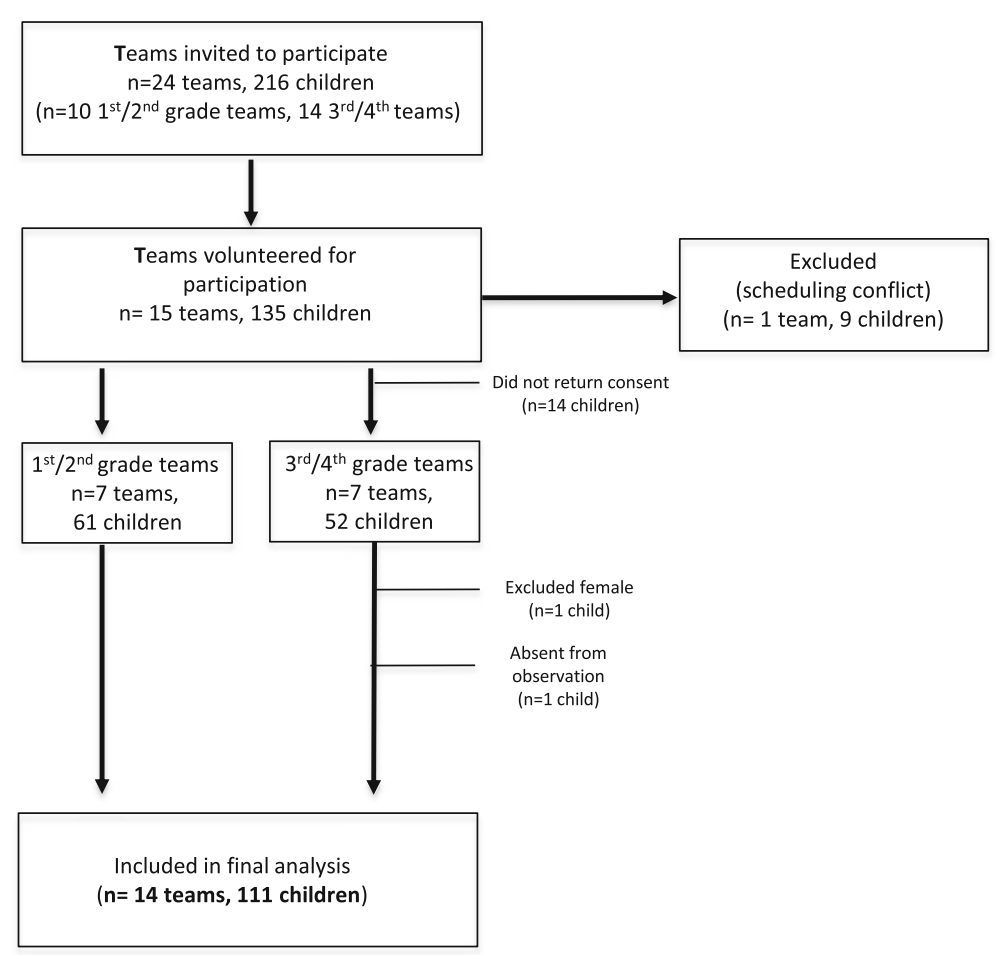

Fig. 1 Consent flow diagram 
Table 1 Coding scheme, definitions, and examples for each contextual variable

\begin{tabular}{|c|c|c|}
\hline Code & Definition & Example \\
\hline Task & The purpose of the time segment. & \\
\hline Warm-up & $\begin{array}{l}\text { Time devoted to a routine execution of physical activity with } \\
\text { a purpose to prepare the individual for engaging in further } \\
\text { activity, but not designed to alter the skill or fitness of the } \\
\text { individual on a long-term basis. Usually occurs in the } \\
\text { beginning of practice [29] }\end{array}$ & $\begin{array}{l}\text { At the beginning of practice the coach has kids do a serious } \\
\text { of dynamic warm-ups and stretches as a group (high knees, } \\
\text { lunges, butt kicks, etc.) }\end{array}$ \\
\hline Free play & $\begin{array}{l}\text { Time during which adult influence of task choice is not } \\
\text { intended [29]. }\end{array}$ & $\begin{array}{l}\text { The coach has footballs for the kids to play with at the } \\
\text { beginning of practice but does not tell the kids what } \\
\text { activities to do or not to do. }\end{array}$ \\
\hline Fitness & $\begin{array}{l}\text { Time where major purpose is to alter the physical state } \\
\text { in terms of cardiovascular endurance, strength or } \\
\text { flexibility }[29,29] \text {. }\end{array}$ & Running sprints \\
\hline Sport Skill & $\begin{array}{l}\text { Adult-led activity time devoted to practice of skills with the } \\
\text { primary goal of skill development }[9,29,31] \text {. }\end{array}$ & Passing drills, flag grabbing drills \\
\hline Game play & $\begin{array}{l}\text { Adult-led time devoted to playground games where skills are } \\
\text { not directly applicable to a competitive sport game and there } \\
\text { is little to no adult instruction or feedback }[9,29,31] \text {. }\end{array}$ & Tag, sharks and minnows \\
\hline Scrimmage & $\begin{array}{l}\text { Adult-led activity time devoted to the refinement and } \\
\text { extension of skills in a sport game where two opposing } \\
\text { teams are created within a team. Minimal interference from } \\
\text { the coach }[9,29,31] \text {. }\end{array}$ & Within a team, the kids are playing a mock football game \\
\hline Strategy & $\begin{array}{l}\text { Time devoted to transmitting information related to rules } \\
\text { and strategy of the sport }[29,31] \text {. }\end{array}$ & $\begin{array}{l}\text { Putting in or practicing an offensive play, defensive } \\
\text { system, etc. }\end{array}$ \\
\hline Management & $\begin{array}{l}\text { Time allocated to managerial and organization activities, time } \\
\text { devoted to team business that is unrelated to instructional } \\
\text { activity }[29,31] .\end{array}$ & Time out, opening huddle, closing huddle \\
\hline Self-care & $\begin{array}{l}\text { Time devoted to washing, using the rest room, or drinking } \\
\text { water. }\end{array}$ & Water break \\
\hline Member Arrangement & The arrangement of the setting members within an segment. & \\
\hline Solitary & Child is doing activity alone $[9,29,31]$. & During a dribbling drill, the child is practice by him or herself. \\
\hline One v One & Child is doing activity with only one additional participant [9]. & $\begin{array}{l}\text { During a blocking drill, each child has a partner and they } \\
\text { take turn blocking. }\end{array}$ \\
\hline Small group & $\begin{array}{l}\text { Child is performing an activity with greater than one other } \\
\text { child, but less than the full team [9]. }\end{array}$ & $\begin{array}{l}\text { During a receiving drill, the full team is split into two groups. } \\
\text { Each group has their own drill to complete, and the groups } \\
\text { are not working together. }\end{array}$ \\
\hline Whole group & All children are participating in an activity $[9,29,31]$. & All kids go to water break at the same time. \\
\hline Setting Demand & Population distribution that influences the system & \\
\hline Optimal & $\begin{array}{l}\text { Time period when there are an equal number of } \\
\text { opportunities to participate as children to participate (i.e., } \\
\text { fosters participation) [20]. }\end{array}$ & $\begin{array}{l}\text { During tag all } 7 \text { kids are playing at the same time, during } \\
\text { warm-up all the kids are on the line at the same time }\end{array}$ \\
\hline Disadvantaged & $\begin{array}{l}\text { Time period when there are a fewer number of opportunities } \\
\text { to participate than children available to participate (i.e., fosters } \\
\text { exclusion) [20]. }\end{array}$ & $\begin{array}{l}\text { During tag, if you get tagged you have to sit on the sideline } \\
\text { until all of the children are out. During a passing drill, only } 1 \\
\text { child is receiving the pass at a time, the rest are waiting in } \\
\text { line behind him. }\end{array}$ \\
\hline
\end{tabular}

assessment. Then, the research team met to modify existing codes and add any codes that were deemed relevant and necessary to the system.

\section{Procedures}

For each of the participating teams $(N=14)$ a research assistant attended a practice to introduce the project to parents, familiarize children with the accelerometers, and collect parent and coach consent and survey information. Only children with parental consent were included in the study.

During September and October, one or more research assistants attended two practices per team, allowing at least 14 days between the first and second practice. Upon arrival to the practice, a research assistant set up a tripod and gave the wearable camera to the head coach. Research assistants placed accelerometers on the right hip of each consenting child as he arrived to practice, and removed it upon practice completion. Practice 
beginning and end times, child's accelerometer on-andoff times, and video start and stop times were recorded using a universally synchronized clock.

\section{Video coding}

Videos were uploaded to a video analysis software (NOLDUS, OBSERVER XT 11.5) to code for contextual variables. Each video was divided into naturally occurring time segments, defined by a change in task, member arrangement, or setting demand, then each segment was coded for each of the three variables (i.e., task, member arrangement, and setting demand). Two research assistants who had completed training and demonstrated reliability ( $\geq 80 \%$ agreement to pre-coded, gold standard video) were randomly assigned one practice per team, with a subsample of videos coded by both research assistants. To ensure inter-rater reliability of the coding scheme, the first four videos (two practices for two teams) were coded by both research assistants and percentage of agreement was calculated. After completion of coding of half of the videos, another four videos (two practices for two teams) were coded by both research assistants, and agreement was again checked to ensure inter-rater reliability remained high. Eight total practices from 4 teams (two practices per team) with a total of 68 segments were coded by both research assistants. Percentage of agreement for start and stop time of segments was $85.3 \%$. Total percentage of agreement for all contextual variables was $91.8 \%$.

\section{Data reduction}

Using a SAS macro developed by the authors, Evenson cut points [27] were applied to physical activity counts to determine physical activity intensity. After video coding, 15-s accelerometer epoch data were matched with the segment start and stop times derived from video observation and were merged with contextual characteristics from video observation. As a result, each segment was assigned a value for physical activity (derived from team accelerometer data), and a category of the contextual variables of task, member arrangement, and member demand.

\section{Statistical analysis}

All statistical analyses were conducted in SAS (Version 9.4; Cary, NC, USA). Mean and standard deviation were calculated for descriptive characteristics of participants and time segments. A strip plot multilevel model with the interaction of team crossed with day created the time segment as the unit of analysis [32]. This model was used to examine the influence of task, member arrangement, and setting demand on physical activity levels (i.e., low-energy stationary behavior, MVPA, VPA) during practice using SAS PROC MIXED [32]. Team, subject, day, and day-byteam were used as random effects, and significance was set at $\alpha=0.05$.

\section{Results}

Mean practice duration was $61.5(S D=8.6)$ minutes. Across all teams, $19.9 \mathrm{~min}(95 \% \mathrm{CI}=17.6,22.3)$ of each practice was spent in MVPA. Approximately $13 \%(95 \% \mathrm{CI}=10.8,15.2)$ of practice time was spent in low-energy stationary behavior, $34 \%(95 \% \mathrm{CI}=31.1$, 36.9) of practice time in MVPA, and $12 \%(95 \% \mathrm{CI}=$ 10.4, 13.6) of practice time in VPA.

\section{Segment characteristics}

Segment characteristics are presented in Table 2. Across all teams 204 time segments were identified. An average of 7 segments (mean $=7.3, S D=2.5$ ) occurred per practice.

\section{Physical activity by contextual variables}

Least-squared means estimates and associations for percentage of time spent in each physical activity intensity for segment types are presented in Table 3.

\section{Task}

Free-play segments had a significantly greater percentage of time in MVPA than fitness, scrimmage, sportskill, and strategy segments. Gameplay segments had a significantly greater percentage of time in MVPA compared to fitness, sport-skill, and strategy segments. Warm-up segments had a significantly greater percentage of time in MVPA than fitness segments.

A significantly greater percentage of low-energy stationary behavior time was found in fitness segments than gameplay segments, sport-skill segments than in free-play, gameplay, and warm-up segments, and in strategy segments than in gameplay segments.

Free-play segments had significantly greater percentage of time in VPA than in sport-skill, and strategy segments. Gameplay segments had a significantly greater percentage of time in VPA than in sport-skill, strategy, and scrimmage segments. Fitness segments had a significantly greater percentage of time spent in VPA than sport-skill, strategy, and scrimmage segments.

\section{Member arrangement}

There were no significant differences for any physical activity intensity between member arrangement types.

\section{Setting demand}

Segments with an optimal setting demand had a significantly greater percentage of time in MVPA and 
Table 2 Segment characteristics

\begin{tabular}{|c|c|c|c|c|}
\hline \multirow{2}{*}{$\begin{array}{l}\text { Segment } \\
(n=204)\end{array}$} & \multicolumn{2}{|l|}{ Frequency } & \multirow{2}{*}{$\begin{array}{l}\text { Mean segment length in minutes } \\
\text { Mean } \pm \text { SD (range) }\end{array}$} & \multirow{2}{*}{$\begin{array}{l}\text { Teams including segment type } \\
\text { in at least one practice } \\
\%(n)\end{array}$} \\
\hline & $\%(n)$ & Number per practice & & \\
\hline \multicolumn{5}{|l|}{ Task } \\
\hline Warm-up & $7.84(16)$ & 0.57 & $3.39 \pm 1.74(1.50-8.00)$ & $71.43(10)$ \\
\hline Fitness & $3.92(8)$ & 0.33 & $1.19 \pm 0.64(0.50-2.25)$ & $28.57(4)$ \\
\hline Free-play & $3.43(7)$ & 0.29 & $5.32 \pm 3.21(1.50-10.75)$ & $35.71(5)$ \\
\hline Game-play & $4.41(9)$ & 0.32 & $8.14 \pm 3.56(1.25-14.75)$ & $50.00(7)$ \\
\hline Management & $18.14(37)$ & 1.32 & $1.78 \pm 1.52(0.25-9.25)$ & $92.86(13)$ \\
\hline Scrimmage & $2.94(6)$ & 0.21 & $21.25 \pm 15.01(5.00-47.50)$ & $42.86(6)$ \\
\hline Self-care & $16.18(33)$ & 1.18 & $1.21 \pm 0.50(0.50-2.25)$ & $92.86(13)$ \\
\hline Sport-skill & $24.14(49)$ & 1.75 & $9.83 \pm 5.87(2.5-26.75)$ & $100(14)$ \\
\hline Strategy & $19.12(39)$ & 1.39 & $16.97 \pm 7.63(1.50-33.00)$ & $100(14)$ \\
\hline \multicolumn{5}{|c|}{ Member Arrangement } \\
\hline One v One & $2.45(5)$ & 0.18 & $6.05 \pm 3.05(2.50-9.50)$ & $35.71(5)$ \\
\hline Small group & $4.41(9)$ & 0.32 & $18.64 \pm 7.82(9.00-33.00)$ & $42.86(6)$ \\
\hline Whole group & $93.14(190)$ & 6.79 & $7.72 \pm 7.85(0.25-47.50)$ & $100(14)$ \\
\hline \multicolumn{5}{|l|}{ Setting Demand } \\
\hline Disadvantaged & $20.12(34)$ & 1.21 & $9.63 \pm 5.36(2.00-25.75)$ & $85.71(12)$ \\
\hline Optimal & $67.16(137)$ & 4.82 & $8.64 \pm 8.89(0.25-47.50)$ & $100(14)$ \\
\hline
\end{tabular}

SD standard deviation

VPA than disadvantaged demand segments, while disadvantaged segments had significantly higher percentage of time spent in low-energy stationary behavior than optimal segments. An additional exploratory analysis indicated that within segment task types, participant demand was associated with varying amounts of the percentage of time spent of MVPA and VPA. Optimal demand segments had higher MVPA and VPA within warm-up (MVPA, $t=3.25, p=0.001$; VPA, $t=3.25, p=0.001$ ) and skill (MVPA, $t=5.12$, $p<0.001$; VPA, $t=3.53, p<0.001)$ than disadvantaged demand segments.

\section{Discussion}

The present study segmented youth sport (YS) practice time by contextual characteristics, described the type and frequency of the segments, and examined the influence of time segments on MVPA. Our findings supported study hypotheses, that: (1) practices would have heterogeneous time segments defined by contextual characteristics, (2) member arrangement and setting demand of the time segment would influence MVPA, and (3) time segments that demanded participation (i.e., optimal demand) would result in greater MVPA compared to segments that fostered exclusion (i.e., disadvantaged demand).

Few other studies $[9,10,33]$ have examined contextual variables during youth sport practice, although comparisons to the present study should be made cautiously. The direct observation systems used by Guagliano and colleagues [10] and Cohen and colleagues [9] both used momentary time-sampling techniques and sequentially followed a set of focal children to determine the average percentage of time spent in various activity intensities and various contexts across a whole practice. In contrast, the present system segmented the practice based on naturally occurring changes in context, rather than pre-determined time intervals, and followed a team, rather than an individual. In addition, some coding scheme variables had operational definitions that differed between the coding systems. For example, the current coding system and OSRAC-YS include a warmup code, whereas SOFIT does not include a code for warm-up, but classifies any warm-up activities as fitness [29]. Further, in order to distinguish between the use of sport-related games and non-sport-related games (e.g., tag) in a YS practice, our system included a code for 'scrimmage', which would be classified as 'gameplay' using SOFIT [10] and OSRAC-YS [9].

Contrary to the present study, Cohen and colleagues [9] found that drills and fitness practice contexts (task in the present study) had the highest percentage of intervals spent in MVPA. This difference is likely attributable to differing observation methods described above. Cohen and colleagues also found small group and individual social contexts 
Table 3 Physical activity intensity by segment type

\begin{tabular}{|c|c|c|c|c|c|c|}
\hline \multicolumn{7}{|c|}{ Percentage of time, adjusted mean $(95 \% \mathrm{Cl})$} \\
\hline & Low-energy stationary behavior & $\begin{array}{l}\text { Differences }^{a} \\
(p<.05)\end{array}$ & VPA & $\begin{array}{l}\text { Differences }{ }^{a} \\
(p<.05)\end{array}$ & MVPA & $\begin{array}{l}\text { Differences }{ }^{a} \\
(p<.05)\end{array}$ \\
\hline \multicolumn{7}{|l|}{ Task } \\
\hline a. Warm-up & $10.63(4.79-16.06)$ & $d, e, h$ & $23.40(19.68-27.12)$ & $e, f, g, h$ & $53.92(46.84-60.96)$ & $b, e, f, g, h, i$ \\
\hline b. Fitness & $15.73(8.84-22.56)$ & $d$ & $20.08(15.00-25.20)$ & $e, f, g, h, i$ & $36.75(27.73-45.82)$ & $a, c, d, e$ \\
\hline c. Free-play & $8.16(0.00-16.43)$ & $\mathrm{e}, \mathrm{h}$ & $17.97(11.53-24.47)$ & $e, h, i$ & $51.51(40.72-62.28)$ & $b, e, f, g, h, i$ \\
\hline d. Game-play & $4.03(0.00-9.88)$ & $a, b, e, g, h, i$ & $23.84(19.49-28.11)$ & $e, f, h, i$ & $53.56(46.35-60.85)$ & $b, e, f, g, h, i$ \\
\hline e. Management & $21.86(17.59-26.21)$ & $a, c, d, f, g, h, i$ & $10.01(7.16-13.04)$ & $a, b, c, d, g$ & $27.81(23.70-33.90)$ & $a, b, c, d, g$ \\
\hline f. Scrimmage & $11.20(4.54-17.86)$ & $e, h$ & $11.12(5.81-16.39)$ & $a, b, d$ & $30.20(21.19-39.22)$ & $a, c, d$ \\
\hline g. Self-care & $14.26(9.79-18.81)$ & $d, e, h$ & 13.08 (9.96-16.24) & $a, b, e, i$ & 37.73 (31.23-44.17) & $a, c, d, e, h$ \\
\hline h. Sport-skill & $17.58(13.29-21.91)$ & $a, c, d, e, f, g, i$ & $10.73(7.76-13.64)$ & $a, b, c, d$ & 31.56 (25.52-37.68) & $a, c, d, g$ \\
\hline \multirow[t]{2}{*}{ i. Strategy } & $12.58(8.29-16.91)$ & $d, e, h$ & $8.48(5.56-11.44)$ & $b, c, d, g$ & 30.62 (24.33-36.87) & $a, c, d$ \\
\hline & Low-energy stationary behavior & $\begin{array}{l}\text { Differences }{ }^{b} \\
(p<.05)\end{array}$ & VPA & $\begin{array}{l}\text { Differences }{ }^{b} \\
(p<.05)\end{array}$ & MVPA & $\begin{array}{l}\text { Differences }{ }^{b} \\
(p<.05)\end{array}$ \\
\hline \multicolumn{7}{|c|}{ Member Arrangement } \\
\hline a. One v One & $12.53(4.46-20.54)$ & None & 16.09 (9.63-22.57) & None & 35.29 (24.72-45.88) & None \\
\hline b. Small group & $13.27(7.12-19.28)$ & None & $10.06(5.20-15.00)$ & None & 35.55 (27.37-43.83) & None \\
\hline \multirow[t]{2}{*}{ c. Whole group } & $15.52(11.97-19.03)$ & None & $12.47(9.76-15.24)$ & None & $34.53(29.21-39.79)$ & None \\
\hline & Low-energy stationary behavior & $\begin{array}{l}\text { Differences }{ }^{c} \\
(p<.05)\end{array}$ & VPA & $\begin{array}{l}\text { Differences }{ }^{c} \\
(p<.05)\end{array}$ & MVPA & $\begin{array}{l}\text { Differences }{ }^{c} \\
(p<.05)\end{array}$ \\
\hline \multicolumn{7}{|l|}{ Setting Demand } \\
\hline a. Disadvantaged & $18.76(14.68-22.92)$ & b & $10.30(7.16-13.44)$ & $b$ & 29.07 (23.22-34.98) & $b$ \\
\hline b. Optimal & $14.21(10.67-17.73)$ & $a$ & $13.21(10.65-15.75)$ & a & 36.06 (30.81-41.39) & a \\
\hline
\end{tabular}

${ }^{\text {a }}$ Significance from mixed effects model (e.g.',a' denotes difference from warm-up)

${ }^{\mathrm{b}}$ Significance from mixed effects model (no significant differences found)

'Significance from mixed effects model (e.g.,'a' denotes difference from disadvantaged)

(participant arrangement in the present study) had the highest percentage of intervals spent in MVPA, whereas the present study found no difference in percentage of time spent in MVPA between participant arrangement types. This may be explained by the low variability of participant arrangements witnessed in the observed sport practices in the present study; 93\% of segments observed were whole group.
To our knowledge, this is the first study to describe PA of segmented YS flag football practice. As depicted in Fig. 2, during a youth sport practice, there are peaks and valleys of activity that occur thereby creating a heterogeneous pattern of children's PA. Averaging PA across an entire youth sport practice loses this pattern of variability, thus periods of time that are spent highly active or inactive cannot be distinguished from the whole

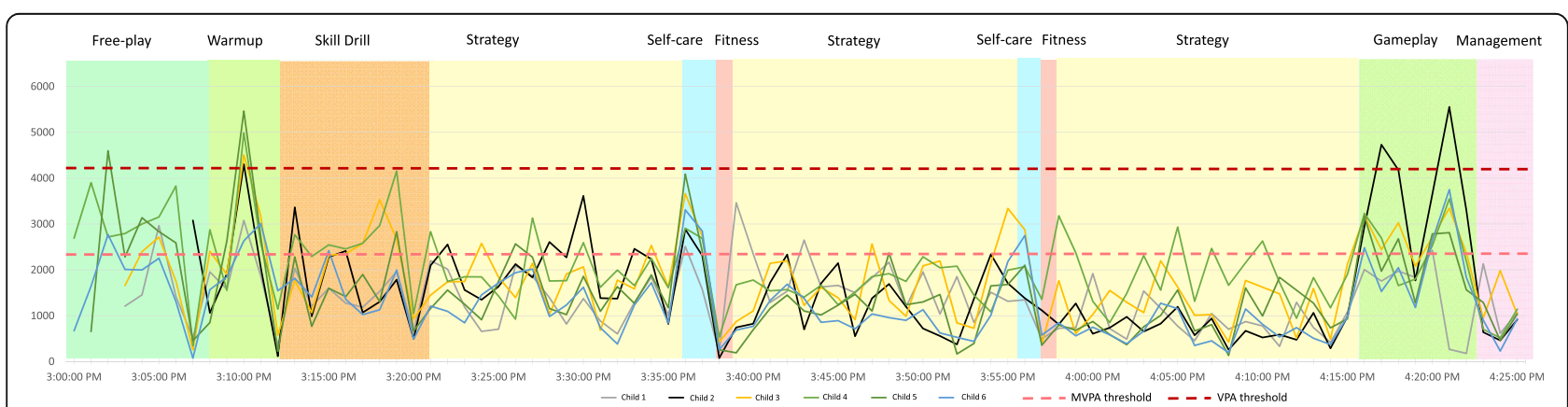

Fig. 2 Physical activity and time segments of one team across one practice 
practice. Identifying periods of time when activity is low during youth sport can help highlight key opportunities to intervene to increase PA during youth sport. Furthermore, by segmenting practice time based on naturally occurring changes in context, we were able to examine the ecological processes that contribute to driving low activity levels.

Our second hypothesis, that segments fostering participation would yield more MVPA than segments that fostered exclusion, was supported. Across all segment task and arrangement types, segments that fostered participation rather than exclusion resulted in higher levels of MVPA, VPA, and lower levels of low-energy stationary behavior time. Barker and Gump [20] first posited that ecological systems that were overloaded encouraged less participation from the whole group. Since then, classroom ecology has built on that premise, particularly in physical education [34]. The principle of setting demand as an ecological process has been applied in interventions across youth settings such as youth sport [35], physical education [36-38], and after-school programs [39] by training leaders to implement strategies such as using small groups, eliminating lines, and modifying elimination games in order to increase the amount of children engaged in physical activity at one time. In the youth sport setting, Guagliano and colleagues [35] demonstrated that a short-term coaching intervention focused on decreasing management time, eliminating lines, and modifying games and drills to offer more opportunities to be physically active was successful at increasing the percentage of time girls spent in MVPA during a basketball camp, compared to a standard-care control group. The present study offers additional support that activities fostering participation are associated with higher levels of MVPA. In the current study, segments that fostered participation had higher levels of MVPA and VPA than those that fostered exclusion; within the task type of warm-up and sport-skill, optimal demand segments had greater MVPA and VPA than disadvantaged segments of the same task type.

Youth sport contributed approximately $20 \mathrm{~min}$ of MVPA toward meeting current physical activity guidelines for children of $60 \mathrm{~min}$ of MVPA per day. Across all teams and segments, approximately $34 \%$ of practice time was spent in MVPA. Though there currently is no recommendation for the percentage of time children should spend in MVPA during youth sport, other youth activity settings, such as physical education, have been recommended to spend at least 50\% of time in MVPA [40]. The present study indicates that segments with the highest percentage of time in MVPA were warm-up, gameplay, and free-play, respectively, all of which were above $50 \%$ of time. Of the 28 observed practices, however, there were only 16 occurrences of warm-up, and were even fewer segments of gameplay $(n=9)$, fitness $(n=8)$, and free-play $(n=7)$. In comparison, management and sport-skill segments had the highest percentage of time spent in low-energy stationary behavior and occurred 37 and 49 times, respectively. This suggests that inserting segments of task types shown to have a high percentage of time in MVPA (e.g., dynamic warm-up, playground games) into a youth sport practice routine and decreasing the frequency of segments with a high percentage of low-energy stationary behavior time could increase the percentage of time children spend in MVPA during practice. In addition, dynamic warm-ups have been recommended for injury prevention $[41,42]$ though less than two-thirds of practices in the present study included a warm-up segment. As youth sport has a large global reach and the potential to make a public health impact, future research should attempt to determine which practice components are most conducive to physical activity, without compromising other goals of a youth sport session (e.g., skill development) and how to train coaches to implement these components into their practice routines.

The present study is not without limitations. Our convenience sample was limited to 14 teams, included only boys, and we observed just two practices per team which creates the potential for selection bias. Additionally, although accelerometers have been shown to be a valid and reliable measure of youth PA, multiple methodological considerations for measurement of MVPA and VPA still lack scientific consensus. In contrast, the study boasts a number of strengths. This study presents a novel approach to combine objectively measured physical activity with direct observation of contextual variables in sport practice to characterize the pattern of PA across a youth sport practice and determine the influence of ecological processes on PA in the youth sport setting. The study had a high consent rate (91\%) across all teams, accelerometer wear time and practice beginning and end times were rigorously defined, and the coding system had high inter-rater reliability.

\section{Conclusion}

In conclusion, the current study suggests that PA during youth sport practice is highly variable across time and is driven by changes in context. Changes in task and setting demand were associated with changes in percentage of time spent in MVPA. Segments within a practice that foster participation are likely to drive practices to have a higher percentage of time spent in MVPA and VPA than those practices that foster exclusion. Further research is needed to identify the combination of types of segments that will optimize physical activity without compromising the other goals of youth sport, such as skill development. As youth sport reaches a large number of children 
world-wide, increasing the percentage of time spent in MVPA during setting time has the potential to create a public health impact.

\section{Abbreviations}

\%time: Percentage of time; CPM: Counts per minute; LPA: Light physica activity; MVPA: Moderate-to-vigorous physical activity; PA: Physical activity; VPA: Vigorous physical activity; YS: Youth sport

\section{Acknowledgements}

The authors would like to thank all the flag football coaches, participants, and parents for volunteering for the study, and Cassandra Knutson for helping with video coding

\section{Funding}

No funding was received for this project.

\section{Availability of data and materials}

The datasets used during the current study are available from the corresponding author on reasonable request.

\section{Authors' contributions}

CRS and DAD developed study idea. CRS, RRR, JMG, and DAD contributed to study design. CRS collected and analyzed data and wrote the manuscript. GAM assisted with statistical analysis. All authors contributed to data interpretation, manuscript revision, and have read and approved the final manuscript.

\section{Ethics approval}

This study was approved by the Kansas State University Institutional Review Board.

\section{Consent for publication}

Not applicable.

\section{Competing interests}

The authors declare that they have no competing interests.

\section{Publisher's Note}

Springer Nature remains neutral with regard to jurisdictional claims in published maps and institutional affiliations.

\section{Author details}

'Department of Kinesiology, Kansas State University, Natatorium 1a, Manhattan, KS 66506, USA. ${ }^{2}$ College of Public Health, University of Nebraska Medical Center, 984365 Nebraska Medical Center, Omaha, NE 68198-4365, USA. ${ }^{3}$ Department of Food, Nutrition, Dietetics and Health, Kansas State University, 213 Justin Hall, Manhattan, KS 66506, USA. ${ }^{4}$ Department of Statistics, Kansas State University, 101 Dickens Hall, Manhattan, KS 66506, USA. ${ }^{5}$ Buffett Early Childhood Institute, University of Nebraska, 2111 S. 67th Street, Suite 350, Omaha, NE 68106, USA.

Received: 23 October 2017 Accepted: 22 January 2018 Published online: 08 February 2018

\section{References}

1. Janssen I, Leblanc AG. Systematic review of the health benefits of physical activity and fitness in school-aged children and youth. Int J Behav Nutr Phys Act. 2010:7:40

2. Troiano RP, Berrigan D, Dodd KW, Masse LC, Tilert T, McDowell M. Physical activity in the United States measured by accelerometer. Med Sci Sports Exerc. 2008:40:181-8.

3. Kraak VA, Liverman CT, Koplan JP, ed, Committee on Prevention of Obesity in Children and Youth. Preventing childhood obesity: health in the balance. National Academies Press; 2005.

4. US Depatment of Health and Human Services. Physical activity guidelines for Americans midcourse report: strategies to increase physical activity among youth. Washington, DC: US Department of Health and Human Services; 2012
5. Nelson TF, Stovitz SD, Thomas M, LaVoi NM, Bauer KW, Neumark-Sztainer D. Do youth sports prevent pediatric obesity? A systematic review and commentary. Curr Sports Med Rep. 2011;10:360-70.

6. Vella SA, Cliff DP, Magee CA, Okely AD. Sports participation and parentreported health-related quality of life in children: longitudinal associations. J Pediatr. 2014;164:1469-74.

7. Eime RM, Young JA, Harvey JT, Charity MJ, Payne WR. A systematic review of the psychological and social benefits of participation in sport for children and adolescents: informing development of a conceptual model of health through sport. Int J Behav Nutr Phys Act. 2013;10:98.

8. Wickel EE, Eisenmann JC. Contribution of youth sport to total daily physical activity among 6-to 12-yr-old boys. Med Sci Sports Exerc. 2007;39:1493-500

9. Cohen A, McDonald S, Mclver K, Pate R, Trost S. Assessing physical activity during youth sport: the observational system for recording activity in children: youth sports. Pediatr Exerc Sci. 2013;26:203-9.

10. Guagliano J, Rosenkranz R, Kolt G. Girls' physical activity levels during organized sports in Australia. Med Sci Sports Exerc. 2013:45:116-22.

11. Leek D, Carlson JA, Cain KL, Henrichon S, Rosenberg D, Patrick K, et al. Physical activity during youth sports practices. Arch Pediatr Adolesc Med. 2011;165:294-9.

12. Schlechter CR, Rosenkranz RR, Milliken GA, Dzewaltowski DA. Physical activity levels during youth sport practice: does coach training or experience have an influence? J Sports Sci. 2017; 35(1):22-8.

13. Tremblay MS, Gray CE, Akinroye KK, Harrington DM, Katzmarzyk PT, Lambert EV, et al. Physical activity of children: a global matrix of grades comparing 15 countries. J Phys Act Health. 2014;11(Supp 1):113-25.

14. Fairclough SJ, Butcher ZH, Stratton G. Whole-day and segmented-day physical activity variability of northwest England school children. Prev Med. 2007;44(5):421-5.

15. Rosenkranz RR, Welk GJ, Dzewaltowski DA. Environmental correlates of objectively measured physical activity and sedentary behavior in after-school recreation sessions. J Phys Act Health. 2011:(8 Suppl 2):214-21.

16. Schlechter CR, Rosenkranz RR, Fees BS, Dzewaltowski DA. Preschool daily patterns of physical activity driven by location and social context. J Sch Health. 2017:87(3):194-9.

17. Trost SG, Rosenkranz RR, Dzewaltowski D. Physical activity levels among children attending after-school programs. Med Sci Sports Exerc. 2008;40:622-9.

18. Tudor-Locke C, Lee SM, Morgan CF, Beighle A, Pangrazi RP. Children's pedometer-determined physical activity during the segmented school day. Med Sci Sports Exerc. 2006;38(10):1732-8.

19. Verbestel V, Van Cauwenberghe E, De Coen V, Maes L, De Bourdeaudhuij I, Cardon G. Within-and between-day variability of objectively measured physical activity in preschoolers. Pediatr Exerc Sci. 2011;23(3):366-78.

20. Barker RG, Gump PV. Big school, small school: high school size and student behavior. 2nd ed. Stanford University Press; 1964.

21. Dudley DA, Okely AD, Cotton WG, Pearson P, Caputi P. Physical activity levels and movement skill instruction in secondary school physical education. J Sci Med Sport. 2012;15(3):231-7.

22. Dzewaltowski, D.A. \& Schlechter, C. R (2017). CLOUDEE: Child Leadership Observation for Understanding Developmental Episodes and Engagement. 2017; http://www.drdaviddzewaltowski.com. Accessed 18 May 2017.

23. Foster KE, Behrens TK, Jager AL, Dzewaltowski DA. Effect of elimination games on physical activity and psychosocial responses in children. J Phys Act Health. 2010;7:475-83.

24. Cain KL, Sallis JF, Conway TL, Van Dyck D, Calhoon L. Using accelerometers in youth physical activity studies: a review of methods. J Phys Act Health. 2013;10:437-50.

25. Trost SG, Loprinzi PD, Moore R, Pfeiffer KA. Comparison of accelerometer cut points for predicting activity intensity in youth. Med Sci Sports Exerc. 2011;43:1360-8.

26. Reilly JJ, Penpraze V, Hislop J, Davies G, Grant S, Paton JY. Objective measurement of physical activity and sedentary behaviour: review with new data. Arch Dis Child. 2008:93:614-9.

27. Evenson KR, Catellier DJ, Gill K, Ondrak KS, McMurray RG. Calibration of two objective measures of physical activity for children. J Sports Sci. 2008;26: 1557-65.

28. Tremblay MS, Aubert S, Barnes JD, Saunders TJ, Carson V, Latimer-Cheung AE, Chastin SF, Altenburg TM, Chinapaw MJ. SBRN terminology consensus project participants. Sedentary behavior research network (SBRN) - terminology consensus project process and outcome. Int J Behav Nutr Phys Act. 2017;14(1):75. 
29. McKenzie TL, Sallis J, Nader P. System for observing fitness instruction time. J Teach Phys Educ. 1991;11:195-205.

30. Doyle W. Classroom organization and management. In: Wittrock MC, editor. Handbook on research on teaching. New York: MacMillam; 1986. p. 392-431.

31. Parker M. Academic learning time-physical education (ALT-PE), 1982 revision. In: Darst PW, Zarkrajsek DB, Mancini VH, editors. Analyzing physical education and sport instruction. Champaign: Human Kinetics; 1989. p. 195-205.

32. Milliken GA. Multilevel designs and their analyses. In: Proceedings 28th annual SAS users group international conference; 2003. p. 263-8.

33. Kanters MA, McKenzie TL, Edwards MB, Bocarro JN, Mahar MT, Martel K, et al. Youth sport practice model gets more kids active with more time practicing skills. Retos. 2015;28:173-7.

34. Siedentop D. Developing teaching skills in physical education. Houghton Mifflin Company: Boston, MA; 1976.

35. Guagliano JM, Lonsdale C, Kolt GS, Rosenkranz RR, George ES. Increasing girls' physical activity during a short-term organized youth sport basketball program: a randomized controlled trial. J Sci Med Sport. 2015;18:412-7.

36. Luepker RV, Perry CL, McKinlay SM, Nader PR, Parcel GS, Stone EJ, et al. Outcomes of a field trial to improve children's dietary patterns and physical activity: the child and adolescent trial for cardiovascular health (CATCH). JAMA. 1996;275:768-76.

37. Sallis JF, McKenzie TL, Alcaraz JE, Kolody B, Faucette N, Hovell MF. The effects of a 2-year physical education program (SPARK) on physical activity and fitness in elementary school students. Sports, play and active recreation for kids. Am J Public Health. 1997;87:1328-34.

38. Webber LS, Catellier DJ, Lytle LA, Murray DM, Pratt CA, Young DR, et al. Promoting physical activity in middle school girls: trial of activity for adolescent girls. Am J of Prev Med. 2008;34:173-84.

39. Dzewaltowski DA, Rosenkranz RR, Geller KS, Coleman KJ, Welk GJ, Hastmann $\mathrm{TJ}$, et al. HOP'N after-school project: an obesity prevention randomized controlled trial. Int J Behav Nutr Phys Act. 2010;7:90.

40. Kohl III HW, Cook HD, editors; Committee on Physical Activity and Physical Education in the School Environment, Food and Nutrition Board, Institute of Medicine. Educating the student body: Taking physical activity and physical education to school. National Academies Press; 2013.

41. Safran MR, Garrett WE, Seaber AV, Glisson RR, Ribbeck BM. The role of warmup in muscular injury prevention. Am J Sports Med. 1988;16:123-9.

42. Soligard T, Myklebust G, Steffen K, Holme I, Silvers H, Bizzini M, et al. Comprehensive warm-up programme to prevent injuries in young female footballers: cluster randomised controlled trial. BMJ. 2008;337:a2469.

\section{Submit your next manuscript to BioMed Central and we will help you at every step:}

- We accept pre-submission inquiries

- Our selector tool helps you to find the most relevant journal

- We provide round the clock customer support

- Convenient online submission

- Thorough peer review

- Inclusion in PubMed and all major indexing services

- Maximum visibility for your research

Submit your manuscript at www.biomedcentral.com/submit
Biomed Central 